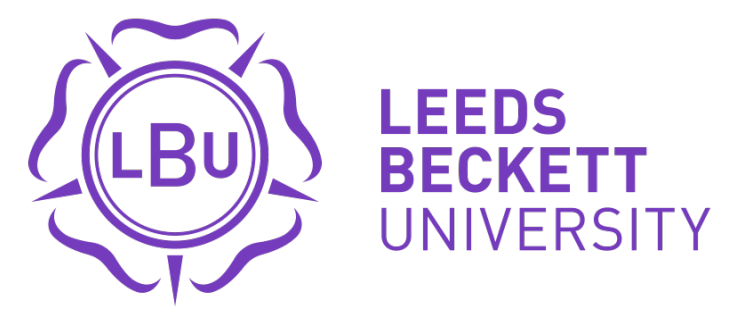

\title{
Citation:
}

Rodrigues, $\mathrm{S}$ and Kaiseler, $\mathrm{M}$ and Pimentel, $\mathrm{G}$ and Rodrigues, $\mathrm{J}$ and Aguiar, $\mathrm{A}$ and Queirós, $\mathrm{C}$ and Cunha, JPS (2018) Ambulatory assessment of psychophysiological stress among police officers: A proof-of-concept study. Occupational Health Science, 2 (2). pp. 215-231. ISSN 2367-0134 DOI: https://doi.org/10.1007/s41542-017-0008-y

Link to Leeds Beckett Repository record:

https://eprints.leedsbeckett.ac.uk/id/eprint/4339/

Document Version:

Article (Accepted Version)

This is a pre-print of an article published in Occupational Health Science. The final authenticated version is available online at: https://doi.org/10.1007/s41542-017-0008-y

The aim of the Leeds Beckett Repository is to provide open access to our research, as required by funder policies and permitted by publishers and copyright law.

The Leeds Beckett repository holds a wide range of publications, each of which has been checked for copyright and the relevant embargo period has been applied by the Research Services team.

We operate on a standard take-down policy. If you are the author or publisher of an output and you would like it removed from the repository, please contact us and we will investigate on a case-by-case basis.

Each thesis in the repository has been cleared where necessary by the author for third party copyright. If you would like a thesis to be removed from the repository or believe there is an issue with copyright, please contact us on openaccess@leedsbeckett.ac.uk and we will investigate on a case-by-case basis. 
6

\section{Ambulatory assessment of psychophysiological stress among police officers: A proof-of-} concept study

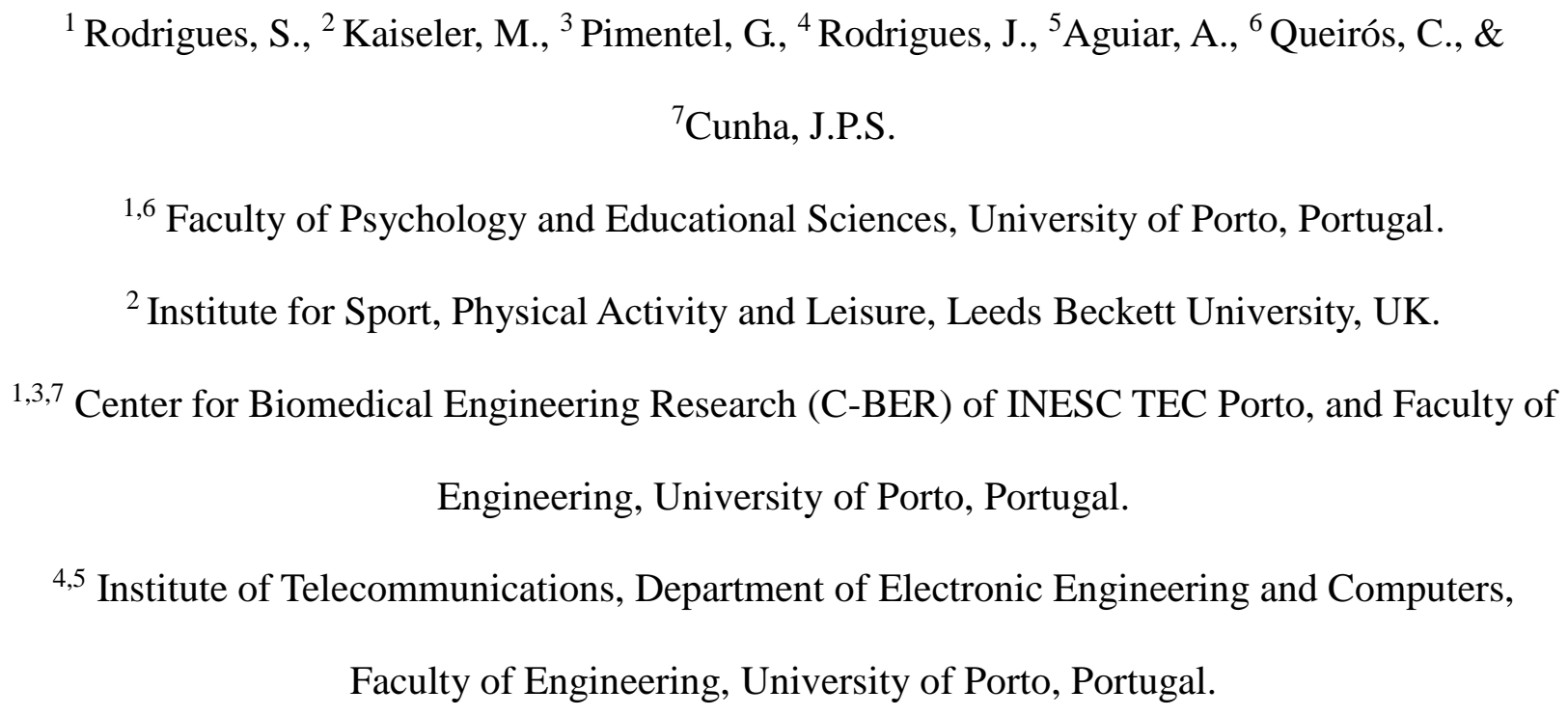

Author Note:

12

Correspondence should be sent to: Susana Rodrigues. INESC TEC - INESC Technology and Science and FEUP - Faculty of Engineering, University of Porto, Portugal. Rua Dr. Roberto Frias s/n Edifício 1, 4200-465 Porto Portugal Telephone: 222094000 Email: susanarodrigues_@hotmail.com. 
Ambulatory assessment of psychophysiological stress among police officers: A proof-of-concept

$$
\text { study }
$$

\section{Abstract}

Occupational stress has been widely recognized as a global challenge and has received increased attention by the academic community. Ambulatory Assessment methodologies, combining psychophysiological measures of stress, offer a promising avenue for future prevention and/or rehabilitation stress research. Considering that policing is well known for being a particularly stressful occupation, Emergency Responders Officers (EROs) stress levels were investigated. Particularly, this study analyzed: (i) physiological stress data obtained during shifts and compared these data with baseline levels (days off), as well as (ii) with normative values for healthy populations; (iii) stress symptoms differences from beginning to end of shift; (iv) stress events and events intensity and (v) the acceptability and feasibility of this proof-ofconcept study in a highly stressful occupation. A Geo-location event system was used to help retrospective accounts of psychological stress, combined with electrocardiogram (ECG) data and mobile self-reports, that include stress symptoms, event types and event intensity. Results suggest that EROs experience high levels of stress (both on-duty and off duty) when compared to healthy populations. Stress symptoms increase from the beginning to end of the shift. However, the mean events intensity was very low. It can be concluded that stress may not always be diagnosed when using merely self-reports. These findings highlight the importance of combining both self-report and physiological stress measures in occupational health contexts. Finally, results confirm the acceptability and feasibility of the multi-method used. Key implications for policy makers and applied practitioners in the area of occupational health and future research directions are discussed. 
43 Keywords: occupational health; ambulatory assessment; geo-location; stress; psychophysiology;

44 Emergency Response Officers.

45

46

47

48

49

50

51

52

53

54

55

56

57

58

59

60

61

62

63

64

65 


\section{Introduction}

The understanding of occupational stress, known as a particular form of stress that

68 involves work (Dewe, O’Driscoll, \& Cooper, 2010), should be of great concern, regarding the

69 risks involved not only for the employee and organization, but also for national economies

70 (Cartwright \& Cooper, 1997). The experience of stress at work is one of the major problems

71 affecting health and safety in Europe (Nakao, 2010). Accordingly, approximately one in four

72 employees suffer from stress-related conditions, and empirical evidence suggests that between

$7350 \%$ and $60 \%$ of work absence days are due to stress associated problems (Maracine, 2010).

74 Stress can be defined as a pattern of negative physiological states and psychological

75 responses that occur in situations that are appraised as taxing or exceeding individual's resources

76 (Lazarus \& Folkman, 1984). Stress is physiologically characterized by an onset of body

77 alterations. Cannon (1914), described this as the "fight-or-flight" response. When a threat is

78 perceived, the autonomic nervous system (ANS) is triggered, the parasympathetic nervous

79 system, that controls homeostasis and the body at rest, is suppressed and the sympathetic nervous

80 system, that controls the body's responses to a perceived threat is activated. Consequently, the

81 secretion of stress-related hormones leads to several physiological responses, including the

82 vasoconstriction of blood vessels, increased blood pressure and breathing rate, increased muscle

83 tension and heart rate (HR) and a decrease in heart rate variability (HRV). Once the threat is no

84 longer present, a sympathovagal balance is reestablished through homeostasis between the

85 parasympathetic and sympathetic system (Taelman, Vandeput, Spaepen, \& Van Huffel, 2008).

86 These mechanisms describe the body's response to a stressful stimulus, by rapidly mobilizing

87 energy and providing an adaptive response. 
Although isolated acute stress responses do not inevitably cause chronic disease, health

89 risks are increased when stressors, or the stress response is frequent and/or persists over long

90 stages (Smyth, Zawadzki, \& Gerin, 2013). Particularly, the continuous activation of the stress

91 systems can lead to serious modifications on the neuro-autonomic and endocrinal balance,

92 creating higher levels of psychological (i.e., depression, anxiety) and physiological problems

93 (i.e., hypertension, coronary heart disease, gastrointestinal malfunctions, metabolic syndrome)

94 (Fenici, Brisinda, \& Sorbo, 2011).

95 Previous studies in occupational health have used a variety of biological markers of

96 stress, such as cortisol (e.g., Collip et al., 2011), HR, HRV (e.g., Dockray et al., 2010), and blood

97 pressure (BP) (e.g., Ewart \& Johnson, 2004). However, there seems to be agreement among the

98 academic community that HRV is the most feasible and reliable way to assess stress

99 physiological responses (Task Force, 1996; Healey \& Picard, 2005). HRV is a noninvasive

100 measure for cardiovascular monitoring and offers the opportunity to simultaneously investigate

101 associations between psychological processes and physiological reactions (Orsila et al., 2008).

102 The HRV refers to cardiac rate alterations, particularly, the complex variations of both

103 instantaneous heart rate and the series of inter-times between consecutive peaks of the R-wave of

104 the electrocardiogram (ECG) (RR intervals). This variation is controlled by the ANS, which

105 through the parasympathetic and the sympathetic branches, is responsible for adjusting the HR in

106 response to external or internal physical or emotional stimulus (e.g., stress). When HRV is lower,

107 it suggests that control mechanisms are not functioning correctly (van Ravenswaaij-Arts, Kollée,

108 Hopman, Stoelinga, \& van Geijn, 1993). Low HRV is of specific interest to psychologists, since

109 it has been linked with poorer self-regulatory mechanisms, due to the connection of the vagal

110 nerve (a key component that determines HRV) to the same neural network involved in emotional 
111 regulation (Appelhans \& Lueken, 2006; Koval, Ogrinz, Kuppens, Van den Bergh, Tuerlinckx, \& 112 Sutterlin, 2013).

113 Despite advances in stress assessment research in the area of occupational health, there

114 are still several challenges to address. First, traditional stress assessment designs are often

115 retrospective and cross-sectional in nature, using mainly self-report measures. Consequently,

116 data collected may be negatively influenced by memory biases or distortions associated with

117 time delays, challenging the validity and reliability of the reports (Segerstrom \& O'Connor,

118 2012). Second, laboratory designs are the common used solution to address the limitations

119 presented above, since they avoid retrospective limitations and can add the rigor of an

120 experimental design (Smith \& Stone, 2003). However, laboratory experiments fail to represent

121 real-world settings, due to the inherent artificial conditions. Finally, there seems to be a lack of

122 reliable physiological methods that can be used to assess stress responses in applied settings,

123 particularly among emergency professions such as policing (Hickman, Fricas, Strom, \& Pope,

124 2011; Kusserow, Amft, \& Troster, 2013).

125 Policing is well known for being a stressful occupation (Strahler \& Ziegert, 2015),

126 therefore the monitoring of stress among police officers working in real world scenarios seems to

127 be a key research priority. Despite this need, such an investigation presents several challenges

128 since stress responses can vary across individuals, situations, stressor typologies and can occur at 129 random times, varying in duration and intensity (Kusserow et al., 2013). Although much work

130 has been conducted to better understand police stress, most of these studies relied mainly on self-

131 report measures. An exception is a study by Hickman et al. (2011) that aimed to investigate

132 police stress using direct real-time and spacially anchored measurements of an officer's response

133 to stressors and the sample consisted of one police officer. Although the study demonstrated that 
134 continuous measurement of police officers cardiac response during a shift is possible, results

135 were limited by the lack of self-report stress data considered. Hence, raising questions on

136 whether observed HR increases were due to psychological stress or merely increases in physical

137 activity.

138 In order to overcome previous limitations in this area and considering that stress is a

139 complex topic, Rodrigues et al. (2015) argued that work stress investigations should be

140 multidisciplinary in nature and should employ multi-methods research approaches. In other

141 words, studies should include accurate and reliable measurements of stress supported by both

142 psychological and physiological data, preferably synchronized, and contain control technologies

143 for possible confounder variables biasing physiological data. Accordingly, Trull and Ebner-

144 Priemer (2013) proposed Ambulatory Assessment as a new research tool that covers a wide range

145 of assessment methods combining self-report, observational, and physiological/behavioral

146 measurements for data collection during real life settings.

147 The current study used a multi-method ambulatory approach to assess EROs`stress

148 levels. Particularly, this study analyzed: physiological stress data obtained during shifts and

149 compared these data with (i) baseline levels (days off), (ii) normative values for healthy

150 populations, (iii) stress symptoms differences from beginning to end of shift, (iv) stress events

151 and events intensity ratings and (v) the acceptability and feasibility of this multi-method

152 approach within this population. This method synchronizes self-reports and physiological stress

153 data collected in real-time during an entire workday. These data were then compared to a non-

154 work day and all physiological data were then compared with normative values. The method

155 included a geo-located event system with ECG data, using user-friendly, non-intrusive mobile

156 and wearable technology. The geo-location system allowed to monitor stress information in a 
157 smartphone, using Global Positioning System (GPS) and contemplated the exact location where

158 the event occurred. The geo-located data were used to facilitate participant's memory retrieval

159 of stressful events (Rodrigues, Kaiseler, Queirós \& Basto-Pereira, 2017). The amount of time

160 participants spent with the equipment, level of compliance, problems/interference reported and

161 their engagement/satisfaction were investigated to test the acceptability and feasibility of this

162 approach.

163 Method

164 Participants

165 Six male EROs from a national police force in the second largest city of Portugal were 166 recruited from a larger study $(N=14)$ assessing stress and coping (Rodrigues et al., 2017). The

167 EROs mean age was 34.57 years $(S D=4.32)$ Participants performed emergency police duties,

168 since they were part of a rapid intervention team that was on-call $24 / 7$ to intervene in critical

169 situations. All participants had over five years of experience in policing. The exclusion criteria

170 for the study were participants having a history of cardiovascular disease and/or taking

171 prescription drugs known to affect cardiovascular function. Participants were instructed to

172 perform no changes in their daily routine, such as sport activities, caffeine, nicotine and food

173 consumption. The study was approved by the University of Porto ethics committee and the

174 Portuguese National Police Force Board. Participants were instructed about the voluntary nature

175 of participation and the confidentiality of their responses.

176 Design

177 A presentation session was organized to explain the aim and protocol of the study,

178 including a psychoeducational component regarding the stress topic. The purpose of this

179 component was to help participants identify stressful events or symptoms. The study instructions 
180 were explained to participants face-to-face by the first author, including a detailed demonstration

181 of procedures. Participants were instructed about the voluntary nature of participation and the

182 confidentiality of their responses.

183 Data was collected during one workday (approximately 8 hours) and one non-work day.

184 For non-working days, participants were required to only use an ECG monitor - VitalJacket ${ }^{\circledR}$ to

185 collect ECG baseline data. During these days, participants were instructed to rest as much as

186 possible and avoid participating in rigorous physical activities. After data collection on non-

187 working days, participants were asked about any stressful events experienced; however, nothing

188 was reported. For the workdays, participants were requested to carry the VitalJacket ${ }^{\circ}$ and a

189 smartphone with a software application (app). EROs provided information regarding stress

190 symptoms, event types and event intensity. A diagram illustrating the study protocol during shifts

191 is shown in Figure 1.

FIGURE 1 ABOUT HERE

193 Materials and measures

$194 \quad$ Physiological data

195 For physiological data collection, a wearable t-shirt incorporating an ECG monitor -

196 VitalJacket ${ }^{\circ}$ was used (Cunha, 2010; 2012) (see Figure 2). The VitalJacket ${ }^{\circ}$ is a wearable bio-

197 monitoring device that provides real-time ECG at a sampling rate of $500 \mathrm{~Hz}$, through one lead

198 and a three axis Accelerometer (ACC). The ACC is an inertial sensor that measures body's

199 acceleration in 3-axis (x,y,z). Particularly, when a body changes its position the ACC is able to

200 measure this change, as well as the intensity of the movement. In terms of participants' activity,

201 the ACC gives a movement/activity intensity indication. In terms of mathematics, a simple

202 quadratic mean (quadratic mean $\left.=\sqrt{\left(a c c_{x}^{2}+a c c_{y}^{2}+a c c_{x}^{2}\right) / 3}\right)$ is computed using all three axis 
$203\left(a C c_{x}, Q C c_{y}, Q C C_{z}\right)$, giving a global activity indicator, independent of the direction of movement.

204 This sensor is in the VitalJacket ${ }^{\circledR}$ system and records the participant movement intensity while

205 monitoring the ECG. Participants did not report any problems regarding the use of the equipment

206 or any interference it may had with their daily activities.

FIGURE 2 ABOUT HERE

Physiological stress was assessed based on different components of HRV. These measures

209 followed the guidelines presented by the Task Force (1996), that are feasible for stress

210 assessment:

211 - AVNN - Average of (normal-to-normal) NN intervals that indicate the number of heart cycles

212 observed per temporal interval.

213 - Root Mean Square of Differences between successive NN intervals (RMSSD) - This value is

214 obtained by first calculating each successive time difference between heartbeats in

215 milliseconds. Then, each of the values is squared and the result is averaged before the square

216 root of the total is obtained. The RMSSD reflects the beat-to-beat variance in heart rate and is

217 the primary time domain measure used to estimate the vagally-mediated changes reflected in

218 HRV (Shaffer, McCraty, \& Zerr, 2014).

219 - pNN50 - the percentage of the number of times per hour in which the change in consecutive

220 normal sinus (NN) intervals exceeds 50 milliseconds; this measure facilitates assessment of

221 parasympathetic (vagal) activity from 24 hour ECG recordings (Ewing, Neilson, \& Travis,

222 1984).

223 - Low Frequency (LF) - is a band of power spectrum ranging between 0.04 and $0.15 \mathrm{~Hz}$. and it

224 is used as an accurate reflection of sympathetic activity (Reyes del Paso, Langewitz, Mulder,

225 van Roon, \& Duschek, 2013). 
226 - High Frequency (HF) - is a band of power spectrum ranging between 0.15 and $0.4 \mathrm{~Hz}$. This

227 represents an index of cardiac parasympathetic tone (Reyes del Paso et al., 2013).

$228-$ LF/HF Ratio - this is the ratio between the power of Low Frequency and High Frequency

229 bands. This measure indicates overall balance between sympathetic and parasympathetic

230 systems. Higher values reflect domination of the sympathetic system, while lower ones

231 suggest domination of the parasympathetic system.

232 Decreased values of AVNN, RMSSD and pNN50 are indicative of stress. Additionally, 233 increased values of LF and LF/HF are also indicators of stress (Castaldo et al., 2015). Table 1

234 describes these HRV parameters and their trend under stress.

TABLE 1 ABOUT HERE

\section{Self-report data}

237 Demographic and medical surveys were used in order to assess participants' current

238 health status and assure that the inclusion criteria were fulfilled. A smartphone with a software

239 application (app), based on the SenseMyCity crowd sensing platform (Rodrigues, Aguiar, \&

240 Barros, 2014) was used. This platform consists of an app using smartphones, that includes a back

241 office and a front office and collects real time data from embedded sensors (e.g., GPS,

242 accelerometer, among others). This app allows participants to describe events, and rate stress

243 levels and symptoms (see Figure 3).

FIGURE 3 ABOUT HERE

In order to understand the cognitive and physical symptoms of stress, a questionnaire was

247 used. This instrument included four questions related with physical ("1- Muscular tension"; "2-

248 Eye fatigue or heavy head"; "3- Nausea, abdominal discomfort and stomach pain"; "4- Difficulty 
249 in maintaining the body straight") and cognitive aspects ("5- Concentration problems"; "6-

250 Difficulty in reasoning, thinking or answering"; "7-Affliction or nervousness"; "8- Difficulty in

251 maintaining control”). Participants were asked to rate each item on a Likert-type scale ranging

252 from 0 - "Not felt at all" to 4- "Extremely felt". These questions were fulfilled in the software

253 app (based on Cohen \& Williamson, 1988) at the beginning and end of the day, aiming to

254 evaluate whether there were alterations in stress symptoms experienced in these two moments.

\section{Event type}

Type of events experienced during shifts were assessed by selecting an option from a

257 stressor checklist (Drug traffic; Public disorder; Neighborhood intervention; Vehicles chase;

258 Inadequate resources; Other). For the purpose of this paper, stressful situations were defined as

259 "a situation that taxes or exceeds one's personal resources or threatens the person wellbeing has

260 the potential to cause stress“(Lazarus \& Folkman, 1984; p.19). The stressor checklist was

261 developed following pilot work (see Rodrigues, Kaiseler, Queirós, \& Basto-Pereira, 2017). This

262 pilot work included a study where 14 ERO's completed daily diaries over 11 working days. Each

263 diary entry included an open-ended question, where participants reported the most common

264 stressors, these answers formed the stressor checklist for this study.

\section{Event intensity}

266 Stress intensity levels were assessed for each event using a 5-point Likert-type scale

267 ranging from 1- "Not at all stressful" to 5 - "Extremely stressful". (Kaiseler, Queirós, Passos, \&

268 Sousa, 2014). Single-item measures were used since they present several benefits, for a detailed

269 review of these please see Fisher, Matthews, and Gibbons (2016).

\section{$270 \quad$ Geo-location data}


All data gathered with the smartphone were exported to a web server to be processed. The

272 processed ECG data, together with the GPS information and the Google Earth platform

273 information were used to display the location history for the full shift for each participant (see

274 Figure 4). Each reported event and other potential stressful events were detected thorough an

275 automated algorithm (following Rodrigues, Kaiseler, Aguiar, et al., 2015) and were imported into

276 Google map. These events were then presented to participants at the end-of-shift interview,

277 aiming to facilitate memory recall and help on a more accurate description of stressful events as

278 described in Rodrigues et al. (2015) (see details in Figure 4).

FIGURE 4 ABOUT HERE

\section{Data analysis}

\section{Physiological data analysis}

A software including an algorithm following Pan Tompkins's work (Pan \& Tompkins, 283 1985) was used to analyze ECG data (Biodevices S.A). All HRV metrics (AVNN, RMSSD, 284 pNN50, LF, LF/HF) were computed using 5 minutes' windows, without overlapping and 285 excluding participant's movement data. HRV metrics were compared during shifts and days off 286 and were also compared to healthy individual's normative values following Voss, Schroeder, 287 Heitmann, Peters, and Siegfried (2015) study. This study included the largest population of 288 healthy individuals $(N=1,906)$ and aimed to analyze age and gender related HRV differences.

\section{Self-report data analysis}

291 subject to a quantitative between-person variation analysis, centered on an event-based approach.

292 Quantitative data from stress symptoms questionnaires were analyzed using a non-parametric

293 hypothesis test - the Wilcoxon Signed Test - conducted using IBM SPSS AMOS (v.22) software. 
294 This test was used to compare participants`stress symptoms mean scores at the beginning and

295 end of shifts. A value of $p<.05$ (two tailed) was considered statistically significant. The internal

296 consistency for the 8 questions of the stress symptoms questionnaire was calculated using

297 Cronbach's alphas. This value provides a coefficient of reliability, and is used as a measure of

298 internal consistency for participants' answers. As recommended these values should be above

2990.70 (Pallant, 2011). In the current study, the Cronbach's alphas were 0.94. Quantitative event

300 intensity levels were calculated considering the mean intensity of each event.

\section{Geo-location event-system analysis}

The geo-located event system analyzed physiological data and monitored potential

303 stressful events based on the cardiac signal retrieved from the VitalJacket@. The ECG data were

304 divided in blocks of 100 seconds and processed using the HRV Toolkit from Physionet

305 (Goldberger et al., 2000). This is a rigorously validated package of open source software for

306 HRV analysis, including visualization of NN interval time series and automated outlier removal.

307 These HRV statistics are well accepted among scholars (e.g., Castaldo et al., 2015). The system

308 extracted HRV metrics, analyzed them and selected the places (using GPS) where a potentially

309 stressful event occurred. These events were selected from all the moments the EROs reported an

310 event on the app, combined with the blocks having the highest algorithms of HRV's LF power,

311 but separated by at least 5 minutes from each other.

\section{Results}

\section{Physiological data}

314 A total of $47 \mathrm{~h}$ of annotated ECG recordings during shifts and $30 \mathrm{~h}$ of data during days off

315 were collected and analyzed, resulting in a total of $77 \mathrm{~h}$ of high medical grade ECG signal. 
Results from AVNN, RMSSD and pNN50 mean values were lower than normative values

317 when participants were on duty. The mean LF/HF ratio was higher than normative values for

318 both shifts and days off (Figure 5). Additionally, two examples of this ECG signal analysis

319 during specific events ("Driving fast"; "Gun situations" - Table 2) provided by the EROs also

320 indicate the presence of physiological stress, considering the high values of LF/HF and low

321 values of AVNN and pNN50 (Figure $6 a$ ) and b).

FIGURE 5 ABOUT HERE

TABLE 2 ABOUT HERE

\section{Self-report data}

\section{Stress symptoms (beginning vs end of shift)} statistically significant change for physical and cognitive stress between the beginning and end of shift symptoms $(Z=-1.60, p>.05$ and $Z=.37, p>.05$, respectively). However, the overall mean

330 score of stress symptoms was higher at the end of the shift $(M=1.73 ; S D=.85)$ compared with the 331 beginning of $\operatorname{shift}(M=1.50 ; S D=.51)$

\section{Event intensity}

Stress events reported and respective stress intensity levels are presented in Table 2.

334 Regarding quantitative stress intensity measures, the stress intensity scores ranged from 0 to 5 ,

335 and the overall mean was $2.1(S D=.99)$. "Suspect escape" was the most intense stress event 336 reported ( $M=4.0)$, followed by "Public disorder $(M=3.0)$ and "Gun situation" $(M=3.0)$.

\section{Geo-located event system}


In total nine events were reported by all EROs using the geo-located system (Table 2).

339 The most cited event type was "neighborhood interventions" (cited three times), followed by

340 "Public disorder" situations (cited two times).

\section{System acceptability and feasibility}

All participants (100\%) carried out the study "kit" during both a shift and a day off and

343 did not report any problems regarding usage or interference with daily activities. Regarding the

344 use of the software app, the majority of participants (five in six; 83\%) forgot to use it after a

345 stressful event. An exception was only one stressful event that was reported on duty by one

346 officer. In what concerns to the use of the software app to assess stress symptoms at the

347 beginning and end of the shift, out of the six, five EROs (83\%) completed the questionnaires on

348 both occasions.

349 Discussion

350 The current study used an ambulatory multi-method approach to assess

351 psychophysiological stress responses in occupational health field and aimed to test the

352 acceptability and feasibility of this method in a sample of EROs. Particularly, this study

353 investigated: (i) physiological data obtained during shifts and compared these data with baseline

354 levels (days off), as well as (ii) with normative values for healthy populations; (iii) stress

355 symptoms differences from beginning to end of shift; (iv) stress events and events intensity and

356 (v) the acceptability and feasibility of this proof-of-concept study among a highly stressful

357 profession.

358 Findings provide an insight on psychophysiological stress levels of EROs when working

359 under real world conditions and confirm the acceptability, feasibility and research potential of the

360 method to be used in similar emergency occupational settings. 
The physiological analysis suggested that EROs experienced high levels of physiological

362 stress, when compared to baseline levels (days off) and when compared to healthy individuals

363 based on the study conducted by Voss et al. (2015). With the exception of Voss and colleagues'

364 paper, it is important to highlight the inexistence of studies including normative values of HRV

365 in large healthy populations. Furthermore, to the best of our knowledge, this is the first study to

366 provide police officers` HRV measures while working in real world conditions, highlighting the

367 original contribution of the findings to this body of knowledge. The physiological analyses

368 indicate stress based on the decreased values of AVNN, RMSSD and pNN50 that reflected a

369 depressed HRV during stress (Castaldo et al., 2015). Finally, the LF/HF ratio was higher than

370 normative values, whether the participants were on-duty or off-duty. Higher values reflect

371 domination of the sympathetic system, while lower ones refer a higher activity from the

372 parasympathetic system, which is compatible with stress responses (Kaur, Bhalla, Bajaj, Sanya,

$373 \&$ Babbar, 2013).

374 Regarding EROs psychological stress symptoms at the beginning compared to end of the

375 shift, findings suggest that there was a minor increase in symptoms. However, this was not

376 statistically significant, probably due to the reduced sample size. The observed tendency supports

377 previous work conducted among Portuguese police officers (e.g., Gomes et al., 2012) showing

378 that physical and cognitive stress symptoms increase during the working day, probably due to

379 experience of stress events. These findings suggest that this population may be experiencing

380 potential cumulative stress effects along the days. Future longitudinal studies are required to

381 confirm this assumption. Additionally, despite the fact that findings suggest the experience of

382 higher stress symptoms at the end of the shift, five out of six EROs participating in the current

383 study did not rate any experienced events as stressful. These findings may suggest that EROs 
384 may not be aware of their stress and its impact on their health and may therefore be unlikely to 385 ask for help.

Accordingly, the results of the ECG analysis (using AVNN, pNN50 and LF/HF metrics)

387 performed during specific events showed that, particularly for "Gun situations", physiological

388 stress was evident in the ECG signal, but this event was not rated as stressful. It is crucial to

389 highlight the importance of the current multi-method approach to understand these compiling

390 findings. Particularly, if only self-report measures were used, one could potentially reach the

391 premature conclusion that EROs do not experience stress events. Hence, combining

392 psychophysiological measures of stress seems to be key to fully understand these professional's

393 occupational health while working under real world conditions.

394 A possible explanation for the fact that EROs do not rate events as stressful could be due

395 to the fact that those events are regularly experienced by them during their shifts, therefore they

396 do not perceive them as stressful, but rather as a routine part of their daily work. An alternative

397 explanation for these findings could be related to the police culture. As stated by Turvey (1995)

398 an officer is expected, by his culture to endure, not to talk about problems or concerns with

399 others. Officers are expected to maintain a surface immunity to their own humanness. When a

400 police officer expresses psychosocial stress, this could be viewed as a weakness, therefore they

401 do normally avoid reporting it (Anshel, 2000). Further qualitative research designs are required

402 to fully understand EROs appraisal of stress events in real world.

403 These findings should be useful for practitioners working with police officers. It is

404 recommended that police practitioners work collaboratively with officers to combat the stigma of

405 mental health problems and treatment, by normalizing help-seeking behavior (Papazoglou \&

406 Andersen, 2014). Additionally, future interventions for this population could include the 
407 development of peer-to-peer programs, since previous research has shown that officers seem

408 reluctant to look for clinicians (Manzella \& Papazoglou, 2014; Waters \& Ursury, 2007).

409 Regarding the acceptability of this study, this was assessed considering the use of the

410 equipment and the engagement with the methodology. All officers carried the study "kit" all day,

411 without reporting any disturbance with the equipment, demonstrating the high acceptability and

412 feasibility of this method. In regards to the use of the geo-located system, in agreement with

413 Rodrigues et al. (2015) findings among bus drivers, this method seems to facilitate memory

414 retrieval among EROs when identifying stressful events. Other possible future advantage in GPS

415 location tagging could be the chance to have this data available in real time allowing for police

416 commanders to have a better control of their teams and it would be easier to identify stressful

417 hotspots (e.g., dangerous neighborhoods, roads). Additionally, from an implementation

418 perspective this system may be a tool to provide citywide "stress maps", spotting areas in need

419 for an emergency response or a local authority intervention. It is recommended that future studies

420 should test the functionality of the system with different professionals working in urban mobile

421 environments.

422 The current ambulatory multi method approach seems to be a promising tool to support

423 first responders' occupational health diagnostic and interventions while also informing

424 management decisions in real time. The current method was key to understand occupational

425 stress among EROs and findings provide key practical and methodological implications.

426 Considering the contemporary increased demands on security, officers`stress monitoring during

427 real world events should be at the forefront of occupational research priorities. Furthermore, our

428 findings suggest that police practitioners should implement healthy routines (e.g., healthy eating 
429 habits, exercise and lifestyle), monthly medical and physical monitoring, and group sessions for

430 stress symptoms detection, aiming to help officers cope more efficiently with daily stress.

431 The current study is not without limitations. First, is the low level of compliance for

432 specific kinds of data, such as the little use of the software app following events. This could be

433 due to the fact that EROs do not perceive events as stressful. Alternatively, they could be too

434 involved in daily events, restricting their capacity for study compliance. A possible solution to

435 overcome this challenge is to have an audible/vibrating alert system in the smartphone, capable

436 of detecting changes in HRV parameters after a stressful event, and warning EROs to fulfill a

437 quick stress survey. Alternatively, participants could report events only at the end of the shift

438 using the geo-located event system. Second, the small sample size, and short time duration of

439 data collection should also be acknowledged as limitations. Finally, it is also important to

440 acknowledge that this type of methodology is resource intensive in terms of software, technology

441 and expertise (i.e., psychology, biomedical and informatics).

442 Despite these limitations, we believe that our $77 \mathrm{~h}$ of geo-located data is one of the largest

443 datasets obtained with police officers, and our results point to some promising avenues for future

444 research and practice that can be used with larger samples and different occupational groups.

445 Hence, findings from the current study extend the body of knowledge of occupational stress

446 assessment and provide a feasible and accurate methodology allowing a holistic approach to

447 stress assessment among highly stressful professions working under real world conditions.

Author note: On behalf of all authors, the corresponding author states that there is no

450 conflict of interest. 
References

453

454 Anshel, M. H. (2000). A conceptual model and implications for coping with stressful events in police work. Criminal Justice Behavior, 27(3), 375-400.

Appelhans, B.M., \& Luecken, L.J. (2006). Heart rate variability as an index of regulated emotional responding. Review of General Psychology, 10, 229-240. doi:

Biodevices, S.A. (n.d.). Certifications. Retrieved from http://www.vitaljacket.com/?page_id=144

460 Cannon, W. B. (1914). The emergency function of the adrenal medulla in pain and the major emotions. American Journal of Physiology, 33, 356-372.

462 Cartwright, S. \& Cooper, C. L. (1997). Managing workplace stress. Thousand Oaks, CA: Sage Publications.

464 Castaldo, R., Melillo, P., Bracale, U., Caserta, M., Triassi, M., \& Pecchia, L. (2015). Acute mental stress assessment via short term HRV analysis in healthy adults: A systematic

Cohen, S., \& Williamson, G. M. (1988). Perceived stress in a probability sample of the United States. In S. Spacapan \& S. Oskamp (Eds.), The social psychology of health

Collip, D., Nicolson, N. A., Lardinois, M., Lataster, T., van Os, J., \& MyinGermeys, I. (2011). Daily cortisol, stress reactivity and psychotic experiences in individuals at above average genetic risk for psychosis. Psychological Medicine, 41, 2305-2315. doi:10.1017/S0033291711000602 
475 Cunha, J.P.S., Cunha, B., Pereira, A.S., Xavier, W., Ferreira, N. \& Meireles, L.A. (2010). Vital 476 Jacket: A wearable wireless vital signs monitor for patients' mobility in Cardiology and Sports. 4th International ICST Conference on Pervasive Computing Technologies for Healthcare. Munich, Germany.

Cunha, J.P.S. (2012). pHealth and Wearable Technologies: a permanent challenge. Studies in Health Technology and Informatics. B. Blobel, P. Pharow and F. Sousa. Amsterdam, IOS Press. 177, 185-195.

Dewe, P. J., O’Driscoll, M. P., \& Cooper, C. L. (2010). Coping with work stress - A review and critique. Chichester: Wiley-blackwell.

Dockray A., Grant, N., Stone, A. A., Kahneman, D., Wardle, J., \& Steptoe, A. (2010) Comparison of affect ratings obtained with ecological momentary assessment and the day reconstruction method. Social Indicators Research, 99, 269-283. doi:10.1007/s11205010-9578-7

Ewart, C. K., \& Jorgensen, R. S. (2004). Agonistic interpersonal striving: social cognitive mechanism of cardiovascular risk in youth? Health Psychology, 23(1), 75-85. doi:10.1037/0278-6133.23.1.75

Ewing, D. J., Neilson, J. M., Travis, P. (1984). New method for assessing cardiac parasympathetic activity using 24 hour electrocardiograms. British Heart Journal 52,

494 Fenici, R., Brisinda, D., \& Sorbo, A. R. (2011). Methods for real-time assessment of operational stress during realistic police tactical training. In J. Kitaeff (Ed.), Handbook of police psychology (pp. 295-262). NY: Routledge Tayler \& Francis Group. 
498 Fisher, G. G., Matthews, R. A., \& Gibbons, A. M. (2016). Developing and investigating the use of single-item measures in organizational research. Journal of Occupational Health Psychology, 21(1), 3-23. doi:10.1037/a0039139

Goldberger, A. L., Amaral, L. A., Glass, L., Hausdorff, J. M., Ivanov, P. C., Mark, R. G., ... Stanley, H. E. (2000). PhysioBank, physioToolkit, and physioNet: components of a new research resource for complex physiologic signals. Circulation, 101, 215-220.

Gomes, P., Kaiseler, M., Queirós, C., Oliveira, M, Lopes, B., \& Coimbra, M. (2012). Vital Analysis: Annotating sensed physiological signals with the stress levels of first responders in action. Paper presented at Engineering in Medicine and Biology Society Annual International Conference of the IEEE, San Diego, USA.

Hovsepian, K., al’Absi, M., Ertin, E., Kamarck, T., Nakajima, M. \& Kumar, S. (2015). Stress: Towards a gold standard for continuous stress assessment in the mobile environment. Proceedings of the 12th ACM international conference on Ubiquitous computing, 493-

515 Hickman, M. J., Fricas, J., Strom, K. J., \& Pope, M. W. (2011). Mapping police stress. Police Quarterly, 14(3), 227-250, doi:10.1177/1098611111413991

Kaiseler, M., Queirós, C., Passos, F., \& Sousa, P. (2014). Stress appraisal, coping, and work engagement among police recruits: an exploratory study. Psychological Reports: Employment Psychology \& Marketing, 114(2), 1-12. doi:10.2466/01.16.PR0.114k21w2 
520 Kaur, S., Bhalla, P., Bajaj, S.K., Sanya, S., \& Babbar, R. (2013). Effect of physical and mental

521 stress on heart rate variability in type-A and type-B personalities. Indian Journal of 522 Applied Basic Medical Sciences, 15(20), 1-13.

523 Koval, P., Ogrinz, B., Kuppens, P., Van den Bergh, O., Tuerlinckx, F., \& Sutterlin, S. (2013). Affective instability in daily life is predicted by resting heart rate variability. PLoS ONE, 8(11), e81536. doi:10.1371/journal.pone.0081536

Kusserow, M., Amft, O., \& Troster, G. (2013). Monitoring stress arousal in the wild. Pervasive

Lazarus, R.S., \& Folkman, S. (1984). Stress, coping and adaptation. New York, NY: Springer.

Manzella, C., \& Papazoglou, K. (2014). Training police trainees about ways to manage trauma computing, 12(2), 28-37. doi:10.1109/MPRV.2012.56

Maracine, M. (2010). The concept of stress and ways of managing it. The Young Economist Journal - Revista Tinerilor Economisti, 8(14), 69-74.

534 Task Force of the European Society of Cardiology and The North American Society of Pacing and Electrophysiology (1996). Heart rate variability standards of measurement, physiological interpretation, and clinical use. European Heart Journal, 17, 354-381.

537 Nakao, M. (2010). Work-related stress and psychosomatic medicine. BioPsychoSocial Medicine, 4(4), 1-8, doi:10.1186/1751-0759-4-4

Orsila R., Virtanen, M., Luukkaala, T., Tarvainen, M., Karjalainen, P., Viik, J., Savinainen, M., \& Nygård, C.H. (2008). Perceived mental stress and reactions in heart rate variability--a pilot study among employees of an electronics company. International Journal of 
Occupational Safety and Ergonomics, 14(3), 275-283.

doi:10.1080/10803548.2008.11076767

Pallant, J. (2011). SPSS Survival manual: a step by step guide to data analysis using SPSS 4th edition. Australia: McGraw Hill Companies.

Papazoglou, K., \& Andersen, J. P. (2014). A guide to utilizing police training as a tool to promote resilience and improve health outcomes among police officers. Traumatology: An International Journal, 20(2), 103-111. doi:10.1037/h0099394

Plarre, K., Raij, A., Hossain, M., Ali, A., Nakajima, M., al'Absi, M., ...Wittmers, L. (2011). Continuous inference of psychological stress from sensory measurements collected in the natural environment. Proceedings of the 10th ACM/IEEE International Conference on Information Processing in Sensor Networks (IPSN), (pp.1-12). Chicago, Illinois.

Reyes del Paso, G. A., Langewitz, W., Mulder, L. J. M., van Roon, A., \& Duschek, S. (2013). The utility of low frequency heart rate variability as an index of sympathetic cardiac tone: A review with emphasis on a reanalysis of previous studies. Psychophysiology, 50(3), 477487. doi:10.1111/psyp.12027

Rodrigues, J. G., Aguiar, A., Barros, J. (2014). SenseMyCity: Crowdsourcing an Urban Sensor. arXiv:1412.2070, 1-10.

Rodrigues, J., Kaiseler, M., Aguiar, A., Cunha, J.P.S., \& Barros, J. (2015). A mobile sensing approach to stress detection and memory activation for public bus drivers. IEEE Transactions on Intelligent Transportation Systems, 99, 1-10, doi:

10.1109/TITS.2015.2445314 
564 Rodrigues, S., Kaiseler, M., \& Queirós, C. (2015). Ecological approaches on stress assessment: A

565

566

567

568

569

570

571

572

573

574

575

576

577

578

579

580

581

582

583

584

585

586

systematic review. European Psychologist, 20(3), 204-226, doi:10.1027/1016-

9040/a000222Rodrigues, S., Kaiseler, M., Queirós, C., \& Bastos-Pereira, M. (2017).

Daily stress and coping among Emergency Response Officers: A case study. International Journal of Emergency Services, 6(2), 1-13. doi:10.1108/IJES-10-2016-0019.

Segerstrom, S. C., \& O’Connor, D. B. (2012). Stress, health and illness: Four challenges for the future. Psychology \& Health, 27(2), 128-140. doi:10.1080/08870446.2012.659516

Shaffer, F., McCraty, R., \& Zerr, C. L. (2014). A healthy heart is not a metronome: an integrative review of the heart's anatomy and heart rate variability. Frontiers in Psychology, 5, 1-19. doi:10.3389/fpsyg.2014.01040

Smith, T. W., \& Stone, A. A. (2003). Ecological momentary assessment research in behavioral medicine. Journal of Happiness Studies, 4, 35-52.

Smyth, J., Zawadzki, M., \& Gerin, W. (2013). Stress and disease: A structural and functional analysis. Social and Personality Psychology Compass, 7(4), 217-227, doi:10.1111/spc3.12020

Strahler, J., \& Ziegert, T. (2015). Psychobiological stress response to a simulated school shooting in police officers. Psychoneuroendocrinology, 51, 80-91, doi:10.1016/j.psyneuen.2014.09.016

Schwab, J.O., Eichner, G., Schmitt, H., Weber, S., Coch, M., \& Waldecker, B. (2003). The relative contribution of the sinus and AV node to heart rate variability. Heart, 89, 337338.

Taelman, J., Vandeput, S., Spaepen, A., \& Huffel, S. V. (2008). Influence of mental stress on heart rate and heart rate variability. IFMBE Proceedings 22, 1366-1369. 
587 Trull, T., \& Ebner-Priemer, U. W. (2013). Ambulatory Assessment. Annual Review of

588 Clinical Psychology, 9, 4.1-4.27, doi:10.1146/annurev-clinpsy-050212-185510

589 Turvey, B. (1995). Police Officers: Control, Hopelessness, \& Suicide," Knowledge Solutions

590 Library, Electronic Publication, Retrieved from http://www.corpus-

$591 \quad$ delicti.com/suicide.html

592 van Ravenswaaij-Arts, C. M., Kollée, L. A., Hopman, J. C., Stoelinga, G. B., \& van

593 Geijn, H.P. (1993). Heart rate variability. Annals of Internal Medicine, 118,

$594 \quad 436-447$.

595 Voss, A., Schroeder, R., Heitmann, A., Peters, A., \& Siegfried, P. (2015). Short-term Heart Rate

596 variability - influence of gender and age in healthy subjects. Plos One, 10(3): e0118308.

597 doi:10.1371/journal.pone.0118308

598 Waters, J. A., \& Ussery, W. (2007). Police stress: history, contributing factors, symptoms, and

599 interventions. International Journal of Police Strategies \& Management, 30(2) 169-188.

600 doi:10.1108/13639510710753199 